\title{
Estimation of Thyroxine Distribution in Man
}

\author{
J. T. Nicoloff and J. Thomas Dowling
}

From the Departments of Medicine of King County Hospital and the

University of Washington, Seattle, Washington, the Veterans Administration

Center, Wadsworth Hospital, and the University of California at

Los Angeles, California

\begin{abstract}
A в S T R A C T A group of 13 normal subjects were evaluated for their extrathyroidal thyroxine distribution. The method employed the measurement of the acute plasma disappearance of a thyroxine-131I tracer and its concomitant uptake into the liver and forearm. The analysis of these parameters allowed the theoretical construction of a four compartmental mathematical model system comprised of the plasma, extracellular fluid, hepatic, and extrahepatic thyroxine pools. The results of this analysis revealed that the exchange of thyroxine from the plasma into the hepatic and extrahepatic cellular fluid spaces appeared, in general, to be rapid, while the uptake into the extrahepatic tissues was relatively slow. The calculated distribution of thyroxine at equilibrium was estimated to be $14 \%$ in liver, $34 \%$ in extrahepatic tissues, and $26 \%$ each in the plasma and extracellular fluid pools in this group of normal subjects.
\end{abstract}

\section{INTRODUCTION}

Knowledge of the rates of equilibration and the distribution of thyroxine in the body fluids and tissues of man is fundamental for an understanding of the action of the hormone on its target organs. The importance of such knowledge in pathological states was demonstrated by Lennon, Enbring, and Engstrom (1). Studying the early rate of disap-

This work was presented in past to the Endocrine Society in June 1964.

Address requests for reprints to Dr. J. T. Nicoloff, University of Southern California School of Medicine, 2025 Zonal Avenue, Los Angeles, Calif. 90033.

Received for publication 28 November 1966 and in revised form 28 August 1967. pearance of ${ }^{131} \mathrm{I}$-labeled L-thyroxine from plasma, they observed an increased rate of disappearance in patients with Graves' disease at all levels of thyroid activity, when compared to non-Graves' disease subjects with comparable thyroidal function, and a slowed rate of disappearance in patients with liver disease and hypothyroidism. Van Middlesworth, Turner, and Lipscomb similarly showed by means of scintiscans performed shortly after the administration of thyroxine-181I that the liver was the major site of isotope concentration in normal subjects and that this concentrating capacity was virtually lost in individuals with severe liver disease (2). Recently, Cavalieri and Searle have confirmed these findings and have attempted to quantitate the amount of thyroxine incorporated into the liver by employing a two compartmental mathematical model system (3). Most attempts to approach the problem of compartmental distribution of thyroxine in man have been based on mathematical models which reproduce segments of the curve produced by the early disappearance of thyroxine-181 I from plasma (3-6). The hypothetical compartments thus produced were then assigned to certain biological fluid or tissue masses which could physiologically account for the compartments.

The purpose of the present study was to develop a simple method for quantifying the distribution of thyroxine- ${ }^{131} \mathrm{I}$ in man. The method is based on simultaneous observation of the distribution of labeled thyroxine from the plasma into the extracellular fluid and intracellular tissue compartments of the body. A mathematical model and direct biopsy method have been applied to validate the 
technique. Finally, a method for assessing the pattern of deiodination of an unequilibrated tracer dose of thyroxine is described, and its results are related to the pattern of distribution of thyroxine and the period required for complete equilibration of the labeled hormone.

\section{METHODS}

Subjects participating in this study were healthy adult men and women in whom there was no history or clinical evidence of thyroid disease. Subjects with liver disease or obesity were excluded. Exceptions were a patient with acute hepatitis and a patient with myxedema. Throughout the period of investigation each patient received 2 drops of a saturated solution of potassium iodide daily to prevent the radioactive iodide derived from the labeled thyroxine recycling to the thyroid gland.

Preparation of labeled thyroxine. ${ }^{120} \mathrm{I}-$ and ${ }^{281} \mathrm{I}$-labeled thyroxine, randomly labeled in the $3^{\prime}$ and $5^{\prime}$ positions, were each obtained from a commercial source (Abbott Laboratories, North Chicago, Ill.) The specific activity ranged between 15 and $40 \mu \mathrm{c}$ per $\mu \mathrm{g}$ when administered. Immediately upon receipt, the labeled thyroxine was diluted in a sterile $0.85 \%$ saline solution containing $1 \%$ human serum albumin and refrigerated. $24 \mathrm{hr}$ prior to use, an appropriate quantity of labeled hormone was dialyzed in the cold against a presterilized cellophane dialysis bag containing IRA-400 anion exchange resin. The volumes of the labeled thyroxine solution and resin bag were roughly maintained at a $3: 1$ ratio. This method has previously been described for the removal of free iodide from labeled albumin (7) and thyroxine solutions (8). The technique serves to render the labeled thyroxine almost devoid of contaminating labeled iodide as judged by subsequent chromatography and radioautography. This is especially true of the ${ }^{205}$ I-labeled thyroxine, which contains only minute quantities of labeled iodide when obtained from the supplier and subsequently manifests negligible radioautolytic breakdown. Some of the labeled thyroxine was also lost to the resin during the dialysis procedure at a rate of approximately $5 \%$ per $24 \mathrm{hr}$ at $4^{\circ} \mathrm{C}$. The pattern of transfer as related to temperature is illustrated in Fig. 1. It will be noted that the rate of transfer is more rapid at higher temperatures. Concentrations of protein-bound iodine (PBI) in the serum were determined by the method of Barker, Humphrey, and Soley (9). The uptake of triiodothyronine by ion exchange resin (RU) was measured, using a standard, commercial resin-sponge system (Triosorb, Abbott Laboratories, North Chicago, IIl.).

The experimental approach of this investigation was to evaluate extrathyroidal thyroxine metabolism, both before and after the equilibrations of the labeled hormone. The disequilibrium studies were primarily designed to assess the distribution and deiodination pattern of tracer thyroxine as it passed into the body fluid and tissue compartments. After equilibration, the net turnover of labeled thyroxine was. determined.

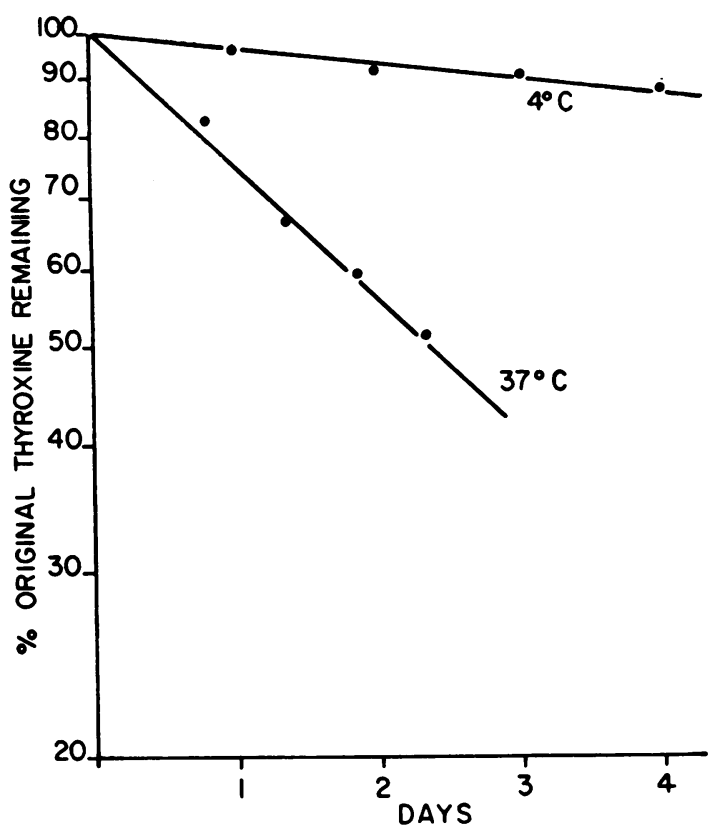

FIGURE 1 The effect of temperature on the rate of transfer of thyroxine-181 I from a $1 \%$ albumin saline solution into a resin-dialysis bag. Resin-dialysis bag is composed of a cellophane dialysis bag containing IRA-400 anion exchange resin.

Disequilibrium phase. This initial portion of the study consisted of a period of $3 \mathrm{hr}$ in which the subjects were positioned in a stationary supine orientation with the left forearm placed in a liquid scintillation chamber (Armac, Packard Instruments, Downers Grove, Ill.). A heavily shielded scintillation probe was then placed over the area of maximum liver dullness as previously determined by percussion. The liver probe consisted of a $2 \times 2$ inch sodium iodide crystal, thallium activated, with a 2 inch straight bore collimation. Uniform geometry of these detectors was maintained throughout this $3 \mathrm{hr}$ period. $20-30 \mu \mathrm{c}$ of thyroxine-- ${ }^{181} \mathrm{I}$ was then administered into the right arm. Heparinized blood samples were then obtained from a more peripheral right arm vein at 5,10 , 15 , and $180 \mathrm{~min}$. All blood samples were obtained without hemastasis. After allowing $6 \mathrm{~min}$ for initial mixing to occur, we obtained $1 \mathrm{~min}$ arm and liver counts at 2 -min intervals for the first half hour and then at 5-min intervals until this portion of the study was completed at $3 \mathrm{hr}$. When a detector similar to the liver probe was positioned over the midthigh, it could serve as a substitute for the arm counter, but doubling of the initial injected dose of labeled thyroxine was required in order to achieve satisfactory counting rates.

Disequilibrium dciodinating ratcs. 2-3 days after the equilibration of the thyroxine ${ }^{131} \mathrm{I}$ tracer, thyroxine ${ }^{128} \mathrm{I}$ was acutely administered intravenously. Hourly urines were obtained for the first $6 \mathrm{hr}$ under stimulus of an oral water load. Serial timed urines were then collected for the 


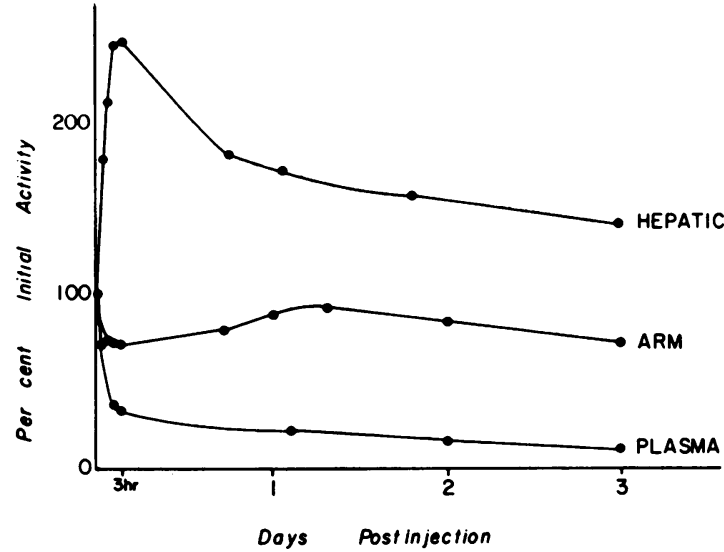

FIGURE 2 The relative radioactivity monitored over the liver and arm and in the plasma after the injection of thyroxine- ${ }^{181} \mathrm{I}$. The extrapolated initial radioactivity value is normalized to $100 \%$ for each parameter, and subsequent activity is expressed relative to this value. Earlier incorporation of labeled thyroxine into the liver as compared to the forearm is evident.

next 4 days. The ratio of ${ }^{125} \mathrm{I}$ and ${ }^{131} \mathrm{I}$ radioactivity of an aliquot of each urine was determined in a well-type scintillation counter employing a dual channel spectrometer. Repeated chromatography of the thyroxine $-{ }^{125} \mathrm{I}$ tracer was performed not only to insure that the tracer had been rendered devoid of contaminating iodide, but also to determine if labeled triiodothyronine was present as an additional contaminant. Chromatography of extracts of the urine samples proved that all the radioactivity was in the form of iodide.

Equilibrium phase. Plasma and arm counts were determined daily for 7-10 days after administration of the tracer. Plasma activity was expressed in terms of per cent of the injected dose per liter. Calculation of the thyroxine turnover rate $(\mathrm{K})$, thyroxine distribution space (TDS) and the disposal rate (D) were determined by the methods described by Sterling and Chodos (10).

Mathematical analysis of labeled thyroxine compartmental distribution. A hypothetical system for the compartmental distribution was constructed, using a mathematical model proposed by Berman and Schoenfeld (11). This system employs a set of differential equations to describe the size and kinetic interplay of the various compartments in the model. The set of differential equations is represented by :

$$
Q_{i}=-\lambda_{i i} Q_{i}+\sum_{j \neq i}^{n} \lambda_{i j} Q_{j}, i=1,2 \cdots, n,
$$

where $Q$, is the amount of the labeled thyroxine in the $i$ th compartment, $\lambda_{i j}$ is the fractional turnover rate from the $j$ th to the $i$ th compartment, $\lambda_{i t}$ is the sum of the fractional rates of loss from the $i$ th compartment, and $n$ is the number of compartments (12). The number and relationship of these proposed compartments to one another were determined on the basis of previous animal experimentations (13) and what appeared to be a logical arrangement on physiological grounds in man. The major assumptions of this model are that the size of the pool and concentration of the labeled hormone in each compartment would not appreciably change during the course of the study and that the mixing time is rapid within a given compartment in relation to the rate of ingress and egress of the isotope from that compartment. The solution of this set of differential equations was accomplished by a digital computer (14) to obtain the best fit for the data when employing the method of least squares.

\section{RESULTS}

After the intravenous injection of labeled thyroxine in man a period of disequilibrium of the isotope occurs which persists for a period of approximately 2 days (15). Fig. 2 portrays the typical pattern of the qualitative alterations in relative radioactivity observed over the liver, forearm, and in the plasma: in normal subjects during the disequilibrium period. In the inital $2 \mathrm{hr}$ after the injection of the isotope a relative accumulation of radioactivity detected by the liver probe and a reciprocal decline in the forearm and plasma were noted. Scintiscans of the chest and abdomen at this time reveal that the only organ which possessed a detectable ability to concentrate the labeled hormone was the liver. The avidity of the normal liver for thyroxine was of such magnitucle that a very satisfactory liver scintiscan could be obtained, as has been described previously by Van Middlesworth, Turner, and Lipscomb(2). No eviclent concentration of the isotope was apparent in the gall bladder, biliary system, heart, kidneys, spleen, or bowel. During the 2nd and 3rd hr the activity over the liver plateaued, as did the arm and plasma counts. Subsequently the uptake in the forearm gradually rose as the liver and plasma counts reciprocally declined during the next $30 \mathrm{hr}$. After the completion of the arm uptake, the slopes of these three parameters became parallel. This slope was linear when plotted semilogarithmically, and described the ultimate disposal slope. Thus, the completion of the forearm uptake apparently marked the achievement of equilibration of the labeled hormone in all body compartments. For purposes of compartmental analysis it will be assumed that the slower equilibrating tissues, as represented by the forearm or thigh, probably portray the manner in which labeled thyroxine equilibrates with most body tis- 

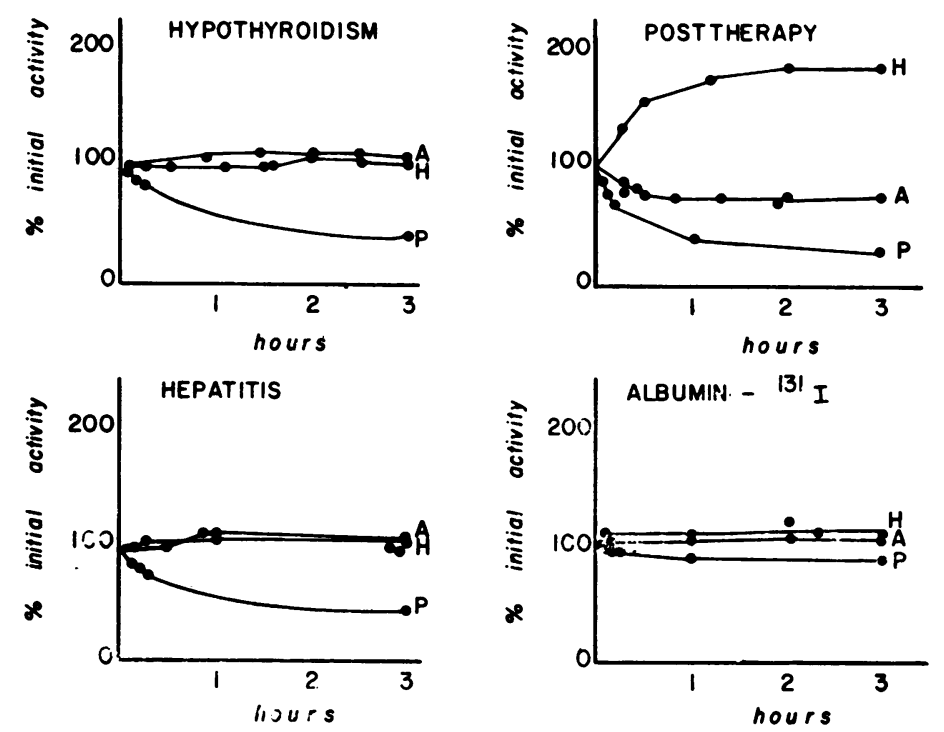

FIGURE 3 The relative early distribution of thyroxine- ${ }^{181} I$ in severe hypothyroidism, treated hypothyroidism, and acute infectious hepatitis as compared with the pattern of albumin- ${ }^{181} I$ in a normal subject. The similarity of the hepatic $(H)$ and forearm $(A)$ curves of the hypothyroidism and acute hepatitis indicates little liver uptakes in these cases. The more rapid drop in the plasma $(P)$ thyroxine- ${ }^{181} \mathrm{I}$ activity than that of albumin- ${ }^{131} \mathrm{I}$ indicates slower penetration of the latter into the extracellular fluid. Treatment of hypothyroidism restores a normal pattern.

sues, excluding the liver, and therefore will be referred to as the extrahepatic thyroxine compartment (EHC). The liver appears to be the major, rapidly equilibrating tissue, and therefore the rapidly equilibrating space will be referred to as the hepatic thyroxine compartment $(\mathrm{HC})$.

The distribution of the labeled hormone into the extracellular fluid space occurs quite rapidly and accounts for the failure of the arm curve in Fig. 2 to drop as rapidly as the plasma curve. Thus, the two major contributors to the early pattern of plasma disappearance appear to be $(a)$ the transcapillary passage of the label into the extracellular fluid thyroxine distribution space (ETDS) and (b) the passage into the hepatic compartment ( $\mathrm{HC}$.

Estimation of the thyroxine plasma space $(P T D S)$. Construction of a line to best fit the three early plasma samples $(5,10$, and $15 \mathrm{~min})$ was performed on semilogarithmic coordinates. The extrapolation of this line to time zero allowed estimation of the plasma thyroxine distribution space (TDS) in a manner similar to that employed to determine the plasma space with radioiodinelabeled serum albumin (RISA). In four subjects this volume closely correlated with the RISA plasma volume. This observation supports the previous findings of Albert and Keating (16) that the plasma space and PTDS are essentially equal.

Estimation of the extracellular fluid thyroxine distribution space (ETDS). It has been assumed in making this approximation that the equilibration of labeled thyroxine in the extracellular fluid is virtually complete by $3 \mathrm{hr}$ and that an insignificant quantity of the label has entered into the extrahepatic intracellular compartment. Additionally, it has been assumed that the arm or leg is a representative site for measurement of this transcapillary passage of labeled thyroxine from the plasma into the extracellular fluid space. Strong support for this latter assumption is evidenced by the finding of a linear arm curve during the $3 \mathrm{hr}$ after the injection of labeled thyroxine in subjects suffering from acute infectious hepatitis and severe hypothyroidism. In these cases no detectable increase in external liver counts could be found, as 
TABLE I

Estimation of Thyroxine Turnover Kinetics and Distribution in Normal Subjects

\begin{tabular}{|c|c|c|c|c|c|c|c|c|c|c|c|c|}
\hline Subject & Sex & Age & PBI & $\mathrm{m}^{2}$ & $\mathrm{~K}$ & TDS & PTDS & ETDS & $\mathrm{HC} / \mathrm{m}^{2}$ & $\mathrm{EHC} / \mathrm{m}^{2}$ & $\mathrm{D} / \mathrm{m}^{2}$ & $\begin{array}{c}\text { Resin } \\
\text { uptake* }\end{array}$ \\
\hline & & & $\begin{array}{c}\mu \mathrm{g} / \\
100 \mathrm{ml}\end{array}$ & & $\%$ & liters & liters & liters & $\mu g I$ & $\mu g I$ & $\mu g I / d a y$ & \\
\hline S. R. & $\mathrm{F}$ & 73 & 7.0 & 1.74 & 9.25 & 9.3 & 2.63 & 2.04 & 44 & 142 & 34.6 & - \\
\hline A. S. & M & 50 & 7.6 & 1.85 & 8.88 & 9.9 & 3.20 & 2.37 & 54 & 123 & 36.0 & - \\
\hline G. S. & $\mathrm{F}$ & 29 & 4.9 & 1.73 & 11.40 & 12.1 & 2.80 & 3.30 & 51 & 119 & 39.0 & 31.8 \\
\hline L. M. & $\mathrm{F}$ & 73 & 5.2 & 1.40 & 8.35 & 9.8 & 2.61 & 2.24 & 44 & 140 & 30.4 & 27.0 \\
\hline L. D. & $\mathrm{F}$ & 74 & 7.1 & 1.34 & 8.45 & 8.4 & 1.92 & 1.93 & 49 & 192 & 37.6 & 26.7 \\
\hline H. O. & $F$ & 25 & 5.3 & 1.40 & 11.55 & 9.1 & 2.22 & 2.18 & 60 & 118 & 39.8 & 31.2 \\
\hline M. B. & $\mathrm{F}$ & 19 & 5.4 & 1.74 & 10.28 & 11.3 & 3.26 & 2.09 & 50 & 135 & 36.0 & 36.0 \\
\hline G. H. & $\mathbf{M}$ & 66 & 5.2 & 1.77 & 13.30 & 9.8 & 2.50 & 1.88 & 45 & 114 & 38.2 & 34.2 \\
\hline H. N. & $\mathrm{F}$ & 25 & 3.8 & 1.70 & 11.70 & 11.5 & 2.60 & 2.65 & 48 & 92 & 30.0 & 31.8 \\
\hline L. H. & M & 45 & 5.5 & 1.95 & 9.25 & 12.9 & 2.00 & 3.72 & 53 & 122 & 33.2 & 33.6 \\
\hline R. L. & M & 32 & 5.2 & 1.96 & 11.20 & 11.1 & 3.45 & 2.45 & 67 & 71 & 33.0 & 31.4 \\
\hline A. S. & M & 60 & 5.1 & 1.71 & 11.35 & 8.4 & 2.08 & 2.09 & 43 & 84 & 28.4 & 33.9 \\
\hline H.S. & M & 39 & 4.4 & 1.66 & 11.60 & 11.0 & 3.07 & 3.13 & 49 & 78 & 33.8 & 30.9 \\
\hline Mean & & 47 & 5.5 & 1.69 & 10.50 & 10.4 & 2.72 & 2.47 & 51 & 118 & 34.6 & 31.7 \\
\hline SD $\ddagger$ & & 20 & 1.1 & 0.02 & 1.53 & 1.4 & .49 & 0.5 & 7 & 32 & 3.7 & 2.85 \\
\hline
\end{tabular}

$\mathrm{PBI}$, protein-bound iodine; $\mathrm{m}^{2}$, surface area in square meters; $\mathrm{K}$, daily fractional rate of thyroxine turnover; TDS, thyroxine distribution space; PTDS, plasma thyroxine distribution space; ETDS, extracellular fluid thyroxine distribution space; $\mathrm{HC} / \mathrm{m}^{2}$, hepatic thyroxine content per square meter of body surface; $\mathrm{EHC} / \mathrm{m}^{2}$, extrahepatic thyroxine content per square meter of body surface; $\mathrm{D} / \mathrm{m}^{2}$, daily turnover of thyroxine per square meter of body surface.

* Triosorb, Abbott Laboratories, North Chicago, Ill.

$\ddagger$ Standard deviation.

is illustrated in Fig. 3. In addition, no concentration of the label in the liver was evident on scintiscan. Therefore, the decline in plasma activity primarily reflects the transfer of the label from the plasma into the extracellular fluid space in these cases. A similar pattern of arm, liver, and plasma curves is produced with labeled albumin in a normal subject, as is seen in Fig. 3. This case simulates the thyroxine-binding protein-labeled thyroxine complex where the liver tissue fails to incorporate the labeled hormone. Thus, the difference in the relative decline of the forearm curve of radioactivity and the plasma curve in the first $3 \mathrm{hr}$ should be a measure of the transfer of labeled thyroxine from the plasma into the extracellular fluid compartment. The calculation of the extracellular fluid thyroxine space (ETDS) may then be expressed as :

$$
\begin{array}{r}
\text { ETDS }=\frac{\left[\text { Arm }_{3 \mathrm{hr}}\right] /\left[\mathrm{Arm}_{0}\right]}{\left[\text { Plasma }_{3 \mathrm{hr}}\right] /\left[\text { Plasma }_{0}\right]} \\
\times \text { PTDS - PTDS }
\end{array}
$$

Where $\left[\mathrm{Arm}_{0}\right]$ and $\left[\mathrm{Plasma}_{0}\right]$ are the extrapolated arm and plasma counts at zero time, $\left[\mathrm{Arm}_{3 \mathrm{hr}}\right]$ and [Plasma ${ }_{3 \mathrm{hr}}$ ] are the arm and plasma counts at $3 \mathrm{hr}$, and PTDS represents the plasma thyroxine distribution space. The results of these calculations reveal that the extracellular fluid thyroxine distribution space $(2.47 \pm 0.58$ liters $)$ almost equals the plasma thyroxine distribution space $(2.72 \pm$ 0.49 liters) in the group of normal subjects (Table I).

Determination of a reference background for qualitative liver uptake of labeled thyroxine. The forearm and plasma curves in the situation where hepatic uptake of the label is not present, as illustrated in Fig. 3, allow insight into what reference for the correction for vascular background would be appropriate for the early liver uptake. It is apparent that the plasma curve would not be a satisfactory reference for background estimation for external liver counting, since a large component of the drop in plasma counts primarily reflects the transfer of the labeled hormone into the extracellular fluid. In contrast, the foreram would appear to be an ideal background reference during the 
first $3 \mathrm{hr}$ postinjection, since it parallels the liver counts when there is no apparent hepatic uptake of thyroxine, as seen in Fig. 2. Using the arm as a reference for background correction, the pattern of equilibration of the labeled thyroxine with the liver was entirely uniform in normal subjects despite differences in the apparent absolute uptake. This pattern is illustrated in Fig. 4. Subsequent to $3 \mathrm{hr}$, the forearm is observed to be slowly incorporating labeled thyroxine, as is seen in Fig. 2, and therefore would become an unsatisfactory reference background source. After this period the rate of change of hepatic background would probably best be described by the rate of change in activity of the plasma compartment.

Estimation of the hepatic content of thyroxine $(H C)$. The major early distribution of thyroxine takes place in the liver and extracellular fluid. Ignoring the small component which may be incorporated in extrahepatic tissues at this time, an estimate of the hepatic distribution space (HTDS) may then be expressed as HTDS $=3 \mathrm{hr}$ TDS (PTDS + ETDS), where $3 \mathrm{hr}$ TDS equals the total thyroxine distribution space at $3 \mathrm{hr}$. The hepatic content ( $\mathrm{HC}$ ) of thyroxine may then be calculated as $\mathrm{HC}=\mathrm{PBI} \quad(\mu \mathrm{g} /$ liter $) \times$ hepatic space (liter).

For comparison of subjects, the hepatic thyroxine content is expressed in terms of body surface area. Body surface area was employed in

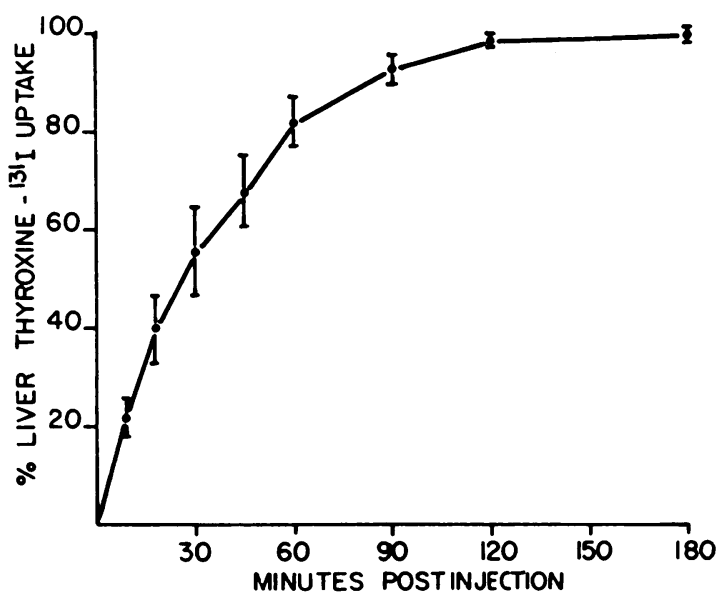

FigURE 4 The qualitative pattern of hepatic thyroxine- ${ }^{121} \mathrm{I}$ uptake relative to the initial and maximal values. The vertical bar represents the standard error of the mean. Note the plateau of the hepatic uptake in the 2-3 hr period.

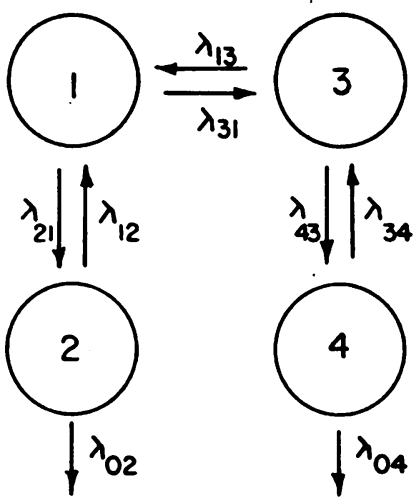

Figure 5 Four compartmental model proposed for determining the pattern of thyroxine distribution. The compartments are labeled as follows: 1, plasma; 2, hepatic; 3 , extracellular fluid; and 4, extrahepatic. $\lambda_{02}$ and $\lambda_{04}$ represent the disposal rates from the hepatic and extrahepatic compartments, respectively.

this instance because other parameters of thyroxine metabolism such as the total hormonal disposal have been found to correlate more uniformly with body surface area than other criteria for intercomparison such as body weight (17). The estimated normal adult hepatic content by this method was calculated to be $50 \pm 7 \mu \mathrm{g}$ ( $\pm 1 \mathrm{SD}$ ) of hormonal iodine per square meter as illustrated in Table I.

Estimation of the extrahepatic content of thyroxine $(E H C)$. It has been assumed for the previous calculations of the hepatic and extracellular fluid thyroxine pools that equilibration of the label and stable hormone was essentially complete by $3 \mathrm{hr}$; therefore, any further enlargement of the total thyroxine distribution space after $3 \mathrm{hr}$ must then result from uptake of labeled thyroxine into the extrahepatic tissues. This space may then be calculated as : extrahepatic thyroxine distribution space $($ EHTDS $)=$ TDS $-($ PTDS + HTDS + ETDS), or, more simply, ETHDS $=$ TDS $-3 \mathrm{hr}$ TDS, and the thyroxine content of the extrahepatic pool (EHC) then would be cletermined as $\mathrm{EHC}=\operatorname{EHTDS}($ liter $) \times \mathrm{PBI}(\mu \mathrm{g} /$ liter $)$.

The results of this determination in normal adult subjects was found to be $118 \pm 32 \mu \mathrm{g}$ of hormonal iodine per square meter (Tahle I). The analysis of extrathyroidal thyroxine clistribution employing this method would be that $50 \%$ of the hormone is present in the plasma and extracellular fluid, and $50 \%$ is present in the borly tissues. The extracellular thyroxine pool would be almost equally 
divided between the extracellular fluid and plasma, while the hormone of the tissue space would be partitioned with $30 \%$ in the liver and $70 \%$ in the extrahepatic tissue compartments. These four major sites of thyroxine distribution are graphically represented in Fig. 5. For purposes of this particular model the various methods of disposal of thyroxine from the hepatic and extrahepatic compartments have not been portrayed, since our data mainly reflect the kinetics of labeled thyroxine distribution.

Application of a mathematical model and liver biopsy to the analysis of compartmental distribution. The solution of our compartmental system was performed in two subjects by employing the program system devised by Berman and Schoenfeld (11). The restrictions employed in the solution of the model were: $(a)$ the plasma compartment volume (PTDS); $(b)$ the form of plasma thyroxine disappearance curve; $(c)$ the obtaining of a close fit for the hepatic uptake curve during the first $3 \mathrm{hr}$ as determined by the qualitative uptake curve normalized to a value directly by liver biopsy at $3 \mathrm{hr} ;(d)$ the total fractional rate of loss from the hepatic and extrahepatic compartments; and $(e)$ the fractional rate of loss of hormone from the hepatic $\left(\lambda_{02}\right)$ and extrahepatic compartments $\left(\lambda_{01}\right)$ proportional to the contents in the respective pools. The liver content of labeled thyroxine in the equilibrated and unequilibrated state was estimated by performing a percutaneous liver biopsy $3 \mathrm{hr}$ after the injection of thyroxine- ${ }^{125} \mathrm{I}$ in a subject previously equilibrated with a thyroxine- ${ }^{131}$ I tracer. The biopsy specimen was suspended in isotonic saline and counted for ${ }^{131} \mathrm{I}$ and ${ }^{125}$ I content and then weighed on an electronic balance. $^{1}$ An estimate of the total liver weight was made on the basis that in a normal adult the average liver weighs $2.63 \%$ of the total body weight (18). Liver size and configuration by scintiscans appeared normal, as did the microscopic

1 Cahn electrobalance. The biopsy specimens weighed $16.5 \mathrm{mg}$ for G.H. and $24.2 \mathrm{mg}$ for A.S. They were counted in an automatic well-type Dual-Channel scintillation counter until a minimum of 10,000 counts for the unequilibrated tracer and 2500 counts for the equilibrated tracer had been accumulated above background. An approximately threefold increase in the quantity of tracer activity was employed in these subjects to obtain adequate counting rates.

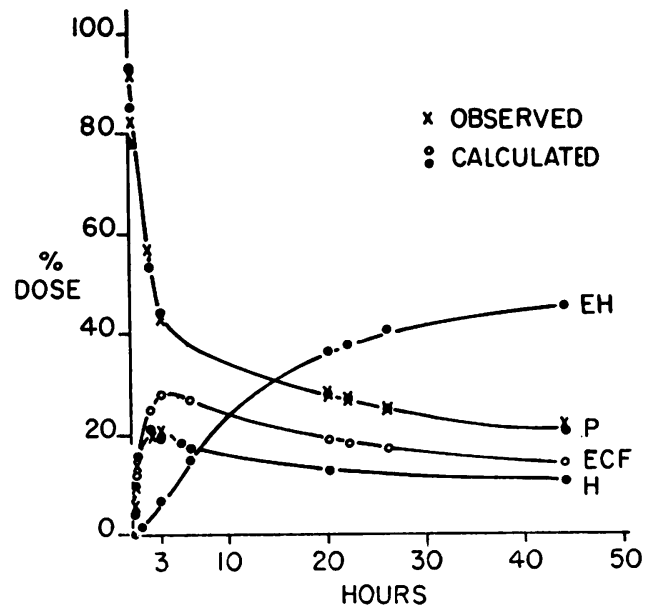

Figure 6 Computer analysis of a typical control subject for the temporal distribution pattern of labeled thyroxine in the major body fluid and tissue compartments. $E H, P, E C F$, and $H$ represent the extrahepatic, plasma, extracellular fluid, and hepatic compartments, respectively.

examination of the biopsy specimens. The temporal changes in labeled thyroxine distribution as determined by computer analysis are displayed in Fig. 6. The solution of the set of differential equations was accomplished by manipulation of the fractional rates of egress and ingress per hour (14) of isotope in order to obtain the best fit to the experimental data. As can be seen in Fig. 6, there is very close correlation between the observed and calculated data in the plasma and hepatic compartments. The fractional rates of transfer per hour $(\lambda)$ employing this model system were found to be for A.S. $\lambda_{12} 0.927, \lambda_{21} 0.889, \lambda_{13} 0.887, \lambda_{: 11} 0.800$, $\lambda_{13} 0.049, \lambda_{34} 0.026, \lambda_{02}$, and $\lambda_{04} 0.0060$; for subject G.H. they were $\lambda_{12} 1.267, \lambda_{21} 0.540, \lambda_{13} 0.766, \lambda_{31}$ $0.541, \lambda_{43} 0.107, \lambda_{34} 0.026, \lambda_{02}$, and $\lambda_{144} 0.0059$. These results may be translated into the transfer rate of micrograms of hormonal iodine per unit hour $(\rho=$ rho $)$ which are, for A.S., $\rho_{12} 157.7, \rho_{21}$ $158.7, \rho_{13} 141.4, \rho_{31} 142.9, \rho_{4: 3} 7.81, \rho_{34} 6.34, \rho_{0.2}$ $1.020, \rho_{0,4} 1.464$, and for G.H., $\rho_{12} 62.10, \rho_{21} 62.39$, $\rho_{13} 60.96, \rho_{31} 62.55, \rho_{34} 6.92, \rho_{43} 8.51, \rho_{0,2} 0.294, \rho_{11,4}$ 1.596. The rate of transfer $(\rho)$ is the product of $\lambda$ times the quantity of hormone which is determined to be in each of the compartments. The rapid ingress and egress of hormone from the hepatic compartment are compatible with the recent findings of Gorman, Flock, Owen, and Paris (19) in isolated rat liver perfusions. The slow 
equilibration of the hypothetical extrahepatic compartment corresponds very closely to the observed delayed uptake in forearm tissues, as shown in Fig. 2. In Table II, comparison of the percentage of labeled isotope present in each compartment at $3 \mathrm{hr}$ after injection and after equilibrium was made for the approximation method, the mathematical model system, and liver biopsy technique. All these methods appear to agree relatively well with one another as to distribution of the labeled thyroxine in both the equilibrated and unequilibrated state.

The pattern of thyroxine deiodination during the disequilibrium period. After the completion of the equilibration of a thyroxine-131I tracer dose a thyroxine- ${ }^{-125} \mathrm{I}$ tracer was then administered intravenously in order to define the relationship between the distribution of the labeled hormone and its deiodination. The method was based on the theoretical consideration that when a pure preparation of thyroxine-125I tracer is administered intravenously, no iodide-125I would appear initially in the urine, since the hormone would not yet have had the opportunity to reach intracellular deiodinating sites. With intracellular uptake of the hormone there then would be deiodination and release of labeled iodide into the extracellular fluid. This newly released ${ }^{125} \mathrm{I}$ appearing in the urine, when expressed as ratio to the ${ }^{131}$ I derived from
TABLE II

Comparison of Results for Various Methods Employed for Estimating Thyroxine Distribution

\begin{tabular}{|c|c|c|c|c|c|c|c|}
\hline \multirow[b]{2}{*}{$\begin{array}{l}\text { Compartment } \\
\text { studied }\end{array}$} & \multirow[b]{2}{*}{ Subject } & \multicolumn{2}{|c|}{$\begin{array}{l}\text { Approxi- } \\
\text { mation } \\
\text { method }\end{array}$} & \multicolumn{2}{|c|}{$\begin{array}{l}\text { Mathema- } \\
\text { tical model }\end{array}$} & \multicolumn{2}{|c|}{ Liver biopsy } \\
\hline & & $3 \mathrm{hr}$ & $\begin{array}{l}\text { Equilib- } \\
\text { rium }\end{array}$ & $3 \mathrm{hr}$ & $\begin{array}{l}\text { Equilib- } \\
\text { rium }\end{array}$ & $3 \mathrm{hr}$ & $\begin{array}{l}\text { Equilib- } \\
\text { rium }\end{array}$ \\
\hline & & \multicolumn{2}{|c|}{$\%$} & \multicolumn{2}{|c|}{$\%$} & \multicolumn{2}{|r|}{$\%$} \\
\hline \multirow[t]{2}{*}{ Plasma } & A.S. & 36.2 & 25.0 & 33.8 & 23.7 & - & - \\
\hline & G.H. & 43.8 & 25.6 & 44.6 & 22.7 & - & - \\
\hline \multirow{2}{*}{$\begin{array}{l}\text { Extracellular } \\
\text { fluid }\end{array}$} & A.S. & 31.0 & 21.6 & 29.8 & 21.3 & - & - \\
\hline & G.H. & 33.0 & 19.0 & 28.2 & 15.6 & 一 & 一 \\
\hline \multirow[t]{2}{*}{ Liver } & A.S. & 32.8 & 22.7 & 32.6 & 22.5 & 32.6 & 20.4 \\
\hline & G.H. & 22.2 & 13.6 & 19.6 & 9.6 & 21.8 & 12.8 \\
\hline \multirow{2}{*}{$\begin{array}{l}\text { Extrahepatic } \\
\text { tissue }\end{array}$} & A.S. & 0 & 30.7 & 3.8 & 32.5 & - & - \\
\hline & G.H. & 0 & 41.8 & 7.6 & 52.1 & - & - \\
\hline
\end{tabular}

the equilibrated tracer, would serve as an index to the relative deiodinating activity of the equilibrating tracer. As illustrated in Fig. 7, timed urines collected sequentially after the injection of the second hormone tracer demonstrated a rapid increase in this ratio for the initial 3 or $4 \mathrm{hr}$ postinjection, subsequently followed by a more gradual increase. The ratio became fixed after $40-62 \mathrm{hr}$, indicating that full equilibration of the two isotopes had been achieved. The time required for establish-

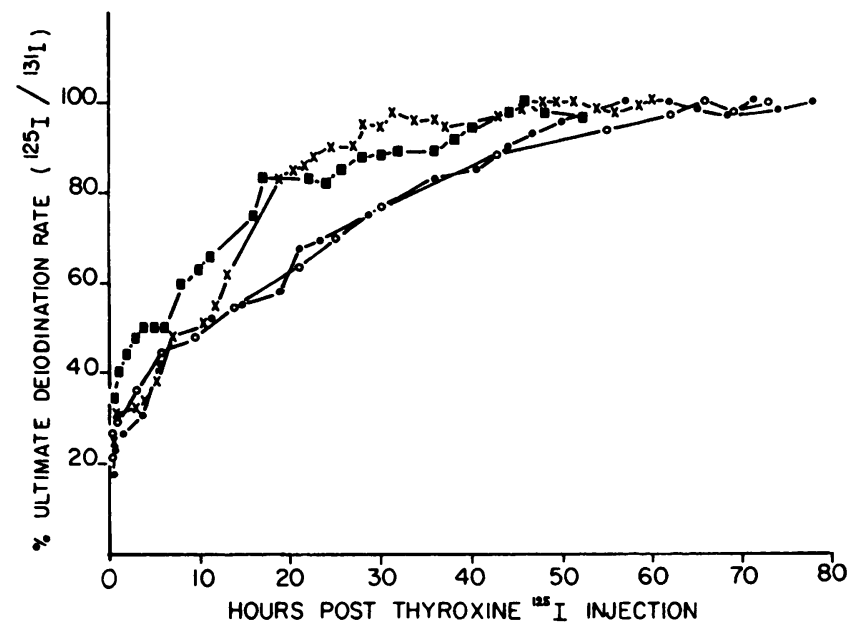

FIGURE 7 The pattern of labeled thyroxine deiodination during the disequilibrium period. The ratio of ${ }^{225} \mathrm{I}$ from an unequilibrated injection of thyroxine- ${ }^{125} \mathrm{I}$ to ${ }^{181} \mathrm{I}$ derived from a previously equilibrated dose of thyroxine ${ }^{-125} \mathrm{I}$ is displayed in four normal subjects. After equilibration is achieved, the fixed ratio is normalized as $100 \%$. 
ing equilibrium supports the previous observations that plasma disappearance slopes for thyroxine do not achieve linearity for approximately 2 days (15).

\section{DISCUSSION}

The simplest formulated model for the distribution of labeled thyroxine appears to be a compartmental system comprised of the plasma, extracellular fluid, hepatic, and extrahepatic spaces. This concept of a four compartmental system appears to be further justified on the basis of studies performed by Roche and Michel in the dog where more direct techniques were employed to ascertain thyroxine distribution during the entire equilibration period (13). They observed that the incorporation rates of thyroxine- ${ }^{131} \mathrm{I}$ into the liver and extracellular fluid (ECF) spaces were equally rapid while tissues other than the liver were generally much slower. The liver and ECF compartments established peak uptakes in 1-2 hr. In contrast, the extrahepatic tissues required $15 \mathrm{hr}$ to accomplish maximal uptake. They also demonstrated that the ECF compartment comprised more than one-third of the total thyroxine distribution when equilibrium was achieved.

The major contrast between the pattern of thyroxine distribution in the dog and man is that in man there is a larger proportion of the thyroxine present in the plasma and liver compartments and a slower rate of equilibration in each of these compartments. The larger plasma compartment and slower rates of equilibration are probably due to the greater amount of circulating thyroxinebinding protein present in man in contrast to that of the $\operatorname{dog}(20)$. Despite these quantitative differences, the gross pattern of thyroxine distribution in clog and man is qualitatively similar. The size of the liver compartment in our subjects at equilibrium was 1.6 liters, while all other extrahepatic tissues constituted 3.6 liters. The ECF and plasma compartments comprised the remaining 5.2 liters of the 10.4 liter distribution volume. Thus in the normal adult one-half of the extrathyroidal thyroxine is within body tissue compartments. Shortly after the injection of the tracer the proportion of the labeled thyroxine in the liver is greater, because the labeled hormone has not yet significantly penetrated the extrahepatic tissues.
At approximately $3 \mathrm{hr}$ the liver achieves its maximal amount of labeled isotope. In our group of normals this concentration averaged $22 \%$ of the injected dose. Friss and Van Middlesworth et al. have previously made the gross estimates that the liver accumulates between 25 and $30 \%$ of the injected dose at 1-3 $\mathrm{hr}$ postinjection $(21,2)$. They employed calibrated scintillation probes placed over the area of the liver. Since no correction was made for the large vascular background of such a probe, these estimates for early hepatic incorporation are somewhat elevated. Recently, we have employed a somewhat more refined method for the external estimation of early hepatic incorporation of labeled thyroxine. ${ }^{2}$ This technique employs a quantitative scintiscan in which a reasonable estimate of vascular background is used. The hepatic uptake at $3 \mathrm{hr}$ postinjection by this method is estimated to be $19.7 \pm 3.9 \%$ ( $\pm=\mathrm{SD}$ ). Failure to appreciate the size of the vascular background of the liver can lead to large errors in the measurement of labeled thyroxin distribution as has been demonstrated by Brown-Grant and Tata in the rabbit (22). They employed albumin- ${ }^{131} \mathrm{I}$ in estimating this error. We have employed albumin- ${ }^{131} \mathrm{I}$ for a similar purpose, as is illustrated in Fig. 3. The difficulty in correcting for the hepatic vascular background and in accounting for the contribution of the extracellular fluid (ECF) to the pattern of the early plasma disappearance of thyroxine- ${ }^{131} \mathrm{I}$ leads to the possible overestimation of the size of the hepatic pool as reported by Pochin (6) and more recently by Cavalieri and Searle (3). The latter authors have suggested that the hepatic pool size ranges between 2.78 and 4.38 liters or $30 \%$ of the entire extrathyroidal pool at equilibrium, while Pochin has estimated it to be $50 \%$ of the extrathyroidal pool. It would appear that two or three compartment mathematical models employed by these authors are not sufficiently restrictive, and the data on which the calculations were based probably do not adequately weigh the contribution of the incorporation of thyroxine- ${ }^{131} \mathrm{I}$ in the ECF and extrahepatic tissue compartments. The fact that the rates of equilibration of the ECF and hepatic compartments are quite similar, as demonstrated in Fig. 6, unfortunately renders the analysis of the early plasma thyroxine- ${ }^{131} \mathrm{I}$ disappear-

${ }^{2}$ Nicoloff, J. T. Unpublished observations. 
ance curve extremely difficult without the acquisition of direct quantitative data relating to the hepatic or ECF uptake. We employed in all cases an estimation of the ECF pool by the analysis of the arm and plasma curves. In the cases of $\mathrm{A}$. S. and G. H., both hepatic and ECF quantitative estimates restricted the nature of the mathematical model solution. Although these restrictions are not as precisely accurate as one might desire, the failure to employ such restrictions may lead to a solution which is far from being unique, as has been previously pointed out by Lewallen, Berman, and Rall (14).

The apparently unique ability of the liver to exchange thyroxine with the plasma rapidly is a poorly understood phenomenon. The liver of the $\operatorname{dog}(13)$, rabbit $(21)$, and the rat $(19,23)$ also demonstrate this characteristic. The influx clearance rate for thyroxine in the adult human liver approximates $40 \mathrm{ml} / \mathrm{min}$ from the data of our kinetic model. This is in contrast to the $5 \mathrm{ml} / \mathrm{min}$ clearance rate for the remainder of the extrahepatic tissues. Although the calculated hepatic clearance may vary considerably from subject to subject, the size of the hepatic thyroxine hepatic pool was found to be fairly constant at $51 \pm 7 \mu \mathrm{g}$ I per square meter in the normal healthy adult subject. The constancy of this figure might imply that it is the content of hormone in liver tissue which may be critical to normal hepatic thyroxine metabolism and not the hepatic distribution volume or circulating level of plasma thyroxine. On the assumption of an average hepatic blood flow of $1500 \mathrm{ml} / \mathrm{min}$, the initial arterial-venous difference across the liver would approximate $2.6 \%$ immediately after the injection of labeled thyroxine. As the hepatic thyroxine pool becomes equilibrated with tracer thyroxine, this difference would disappear as efflux rate approaches influx rate. Recently, Appleton and Dowling (24) have directly measured the arterial-hepatic venous difference and have verified that the observed value closely approximates the theoretical value for net hepatic uptake. The mechanisms whereby the liver concentrates and exchanges thyroxine rapidly are not clearly understood.

The fact that the plasma thyroxine pool essentially equals the plasma volume was not surprising in view of the fact that at any one moment ap- proximately $99.9 \%$ of circulating thyroxine is protein bound (25). Also to be expected is that the extracellular thyroxine pool nearly equals that of the plasma pool. This is approximately true also for albumin (26), which is similar in size to thyroxine-binding globulin and thyroxine-binding prealbumin (27).

The rate at which thyroxine equilibrates with the extrathyroidal fluids and tissues is somewhat slower than has been previously appreciated. The deiodination rate of an unequilibrated injection of thyroxine-125 I dose did not achieve a constant value in relation to a previously equilibrated injection of thyroxine- ${ }^{131} \mathrm{I}$ for $40-66 \mathrm{hr}$ in normal subjects, as is illustrated in Fig. 7. A portion of this delay may be due to the equilibration of the iodide released from deiodination with the extrathyroidal iodide pool, but this would probably not delay equilibration by more than $8 \mathrm{hr}(25)$. The deiodination occurring during the first 3-5 hr primarily represents tissue uptake and deiodination by the hepatic tissues, while the subsequent increase in deiodination rate is governed by the incorporation and deiodination in the extrahepatic compartment.

The protracted equilibration of the extrahepatic intracellular compartment as clescribed in the mathematical model in Fig. 6 is paralleled by the gradual augmentation of the deiodination rate of the unequilibrated thyroxine isotope. Indeed, during the period when the hepatic uptake of the injected isotope tracer is maximal, the deiodination rate ranges only between approximately $30-50 \%$, thus underscoring the major role of the extrahepatic tissues in thyroxine metabolism. The source of hormone to be incorporated into the extrahepatic tissue compartment is derived from plasma, extracellular fluid, and hepatic pools. The reversibility of the thyroxine pool in the hepatic compartment has recently been demonstrated in the isolated perfused rat liver by Gorman and coworkers (19). The lowered percentage of the injected dose of the equilibrated tracer versus the content at $3 \mathrm{hr}$ in subjects A. S. and G. H. liver biopsy specimens demonstrates the reversible nature of the hepatic uptake.

\section{ADDENDUM}

Since this manuscript was prepared, Oppenheimer, Bernstein. and Hasen (28) have published a two compart- 
mental analysis system for the peripheral distribution of thyroxine. Their results support the previous observation of Cavalieri and Searle (3) in that they conclude that the normal hepatic thyroxine space is about 3.5 liters. They further conclude that the liver concentrates some $78 \%$ of all the intracellular stores of thyroxine. One of the major assumptions of this study is that thyroxine is transferred into the extracellular space primarily as a macromolecule, attached to its specific binding protein. Thus, they employ the concept of correcting for the rate of egress of tracer thyroxine into the extracellular fluid by measuring the rate of loss of albumin- ${ }^{125} \mathrm{I}$ from the vascular compartment. A study performed on a subject with a pleural effusion associated with congestive heart failure was used to support the employment of this correction. In this study the appearance of albumin- ${ }^{125} \mathrm{I}$ and thyroxine- ${ }^{181} I$ in the effusion was measured for the initial $4 \mathrm{hr}$ postinjection period. It was observed that the rates of ingress and egress of labeled albumin and thyroxine were similar in this particular subject. The initial transfer rate of thyroxine exceeded that of albumin by only $25 \%$. This study supported the concept of these authors that the transfer of thyroxine into the ECF was, in general, very slow and paralleled that of albumin. As a consequence of this slow transfer rate of thyroxine into the extracellular fluid, kinetic analysis of thyroxine distribution revealed that the extrahepatic tissues could only contain $8.2 \%$ of the entire extrathyroidal thyroxine pool.

In contrast, our data suggest that there is a substantial uptake of labeled thyroxine into other body compartments including the forearms as well as the liver during the initial $3 \mathrm{hr}$ after the injection of the thyroxine tracer. The relative rate of the forearm uptake of labeled thyroxine in a control subject is shown in Fig. 8. It seems reasonable to assume that the major component of the early uptake of the tracer in the forearm was primarily due to the entry of the tracer into the ECF and that the sub-

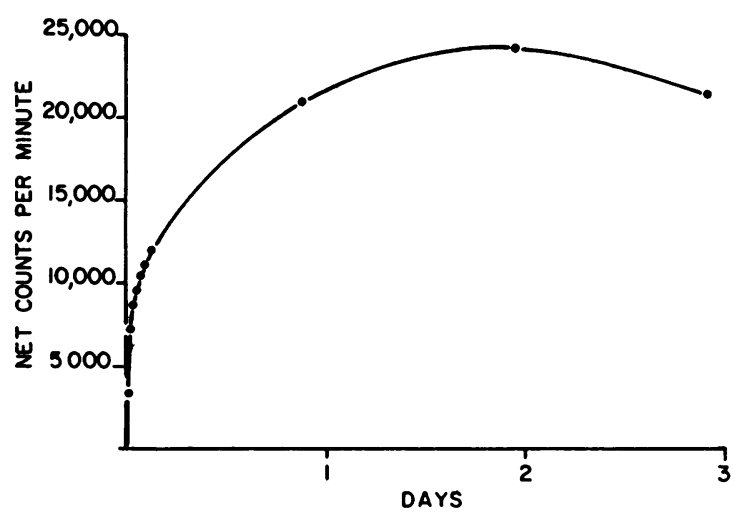

FIGURE 8 The forearm uptake of thyroxine- ${ }^{181} \mathrm{I}$ in a normal subject. The net forearm uptake is estimated as the absolute forearm activity minus the estimated plasma activity in the forearm. The forearm plasma activity was assumed to be the ( 0 time forearm activity $\times$ plasma activity at time $t$ )/plasma activity at time 0 . sequent uptake is due to tissue incorporation. This view is supported indirectly by the observation that the relative deiodination rate does not achieve its peak value until complete equilibration of the tracer is established, as is shown in lig. 7 .

The solution to these apparently conflicting results unfortunately cannot be fully resolved at the present time. It would seem wise, in view of the evidence previously cited in work on the dog (13) and in our own findings, to keep an open mind in regards to the size, rate, and equilibration of ECF until more direct and physiological data can be obtained. Additionally, Oppenheimer et al. (28) attempted to obtain, in a manner similar to that employed in our study, a direct estimate of the hepatic content of labeled thyroxine by liver biopsy. In four subjects, the values ranged from 11.9 to $51.9 \%$ of the administered dose with an average of $42.6 \%$ in the three subjects thought to have a normal liver biopsy. Our expected average value would be $22 \%$, which is the range we observed in our two biopsy cases. No ready explanation for these differences is apparent at the present time, except that this technicue is admittedly a very crude one. The results of quantitative hepatic scintiscans would appear to support the lower figure. ${ }^{3}$

\section{ACKNOWLEDGMENTS}

The authors wish to express their gratitucle to $\mathrm{Mr}$. Dwight Warren for his excellent technical assistance and to Mr. Hojat Rostami for assistance with the mathematical analysis. The computer analysis was performed at the Health Science Computing Facility at the UCLA medical Center, Los Angeles.

This work was supported in part by Public Health Grants AM-05825 and 2A-5331 from the National Institute of Arthritis and Metabolic Discases, Bethesda, Maryland, and the Clinical Investigatorship Program, Veterans Administration Center, Los Angeles, Calif., and Army Contract DA-49-193-MD-2420, issued by the Office of the Surgcon General, Department of the Army, Washington, D. C.

\section{REFERENCES}

1. Lennon, E. J., N. H. Engbring, and W. W. Engstrom. 1961. Studies of the rate of disappearance of labeled thyroxine from the intravascular compartment. J. Clin. Invest. 40: 996.

2. Van Middlesworth, L., J. A. Turner, and A. Lipscomb. 1963. Liver function related to thyroxine metabolism. J. Nucl. Med. 4: 132.

3. Cavalieri, R. R., and G. L. Searle. 1966. The kinetics of distribution between plasma and liver of ${ }^{131}$ I-labeled L-thyroxine in man: Observations of subjects with normal and decreased serum thyroxine-binding globulin. J. Clin. Invest. 45: 939.

4. Blomstedt, B., and L. O. Plantin. 1965. The extrathyroidal distribution of ${ }^{131} \mathrm{I}$ thyroxine. Acta Endocrinol. 48: 536.

${ }^{3}$ Nicoloff, J. T. Unpublished observations. 
5. Rall, J. E., J. Robbins, D. Becker, and R. W. Rawson. 1953. The metabolism of labeled L-triiodothyronine, L-thyroxine and D-thyroxine. J. Clin. Invest. 32: 596. (Abstr.)

6. Pochin, E. E. 1964. Liver concentration of thyroid metabolites. In Dynamic Clinical Studies with Radioisotopes. R. M. Kniseley and W. N. Tauxe, editors. AEC TID-7678, Oak Ridge. 413.

7. McCall, M. S., and M. F. Camp. 1961. A simple technique for prolonging the storage life of $\mathrm{I}^{131}$-labeled proteins and polymers. J. Lab. Clin. Med. 58: 772.

S. Ingbar, S. H., L. E. Braverman, N. A. Dawber, and G. Y. Lee. 1965. A new method for measuring the free thyroid hormone in human serum and an analysis of the factors that influence its concentration. J. Clin. Invest. 44: 1679.

9. Barker, S. B., M. J. Humphrey, and M. H. Soley. 1951. The clinical determination of protein-bound iodine. J. Clin. Invest. 30: 55 .

10. Sterling, K., and R. B. Chodos. 1956. Radiothyroxine turnover studies in myxedema, thyrotoxicosis, and hypermetabolism without endocrine clisease: J. Clin. Invest. $35: 806$.

11. Berman, M., and R. Schoenfeld. 1956. Invariants in experimental data on linear kinetics and the formulation of models. J. Appl. Phys. 27: 1361.

12. Berman, M. 1960. Application of differential equations to the study of thyroid systems. In Proceedings of the 4th Berkeley Symposium on Mathematical Statistics and Probability. University of California. 4: 87.

13. Roche, J., and R. Michel. 1960. On the peripheral metabolism of thyroid hormone. Ann. N. Y. Acad. Sci. 86: 454.

14. Lewallen, C. G., M. Berman, and J. E. Rall. 1959. Studies of iodo-albumin metabolism. I. A mathematical approach to the kinetics. J. Clin. Invest. 38: 66.

15. Sterling, K., J. C. Lashof, and E. B. Man. 1954. Disappearance from serum of $\mathrm{I}^{131}$-labeled $\mathrm{L}$-thyroxine and L-triiodothyronine in euthyroid subjects. J. Clin. Invest. 33: 1031.

16. Albert, A., and F. R. Keating, Jr. 1949. Metabolic studies with $\mathrm{I}^{121}$ labeled thyroid compounds. Comparison of the distribution and fate of radioactive $d-l$ thyroxine after oral and intravenous administration in the human. J. Clin. Endocrinol. Metab. 9: 1406.

17. Haddad, H. M. 1960 . Rates of $I^{130}$-labeled thyroxine metabolism in euthyroid children. J. Clin. Invest. 39: 1590.

18. Behnke, A. R., Jr. 1958. The liver in relation to the body as a whole in liver function. In Liver Function: A symposium on approaches to the quantitative description of liver function. R. W. Brauer, editor. American Institute of Biological Sciences, Washington, D. C. 43.

19. Gorman, C. A., E. V. Flock, C. A. Owen, Jr., and J. Paris. 1966. Factors affecting exchange of thyroid hormones between liver and blood. Endocrinology. 79: 391.

20. Robbins, J., and J. E. Rall. 1957. The interaction of thyroid hormones and protein in biological fluids. $R e$ cent Progr. Hormone Res. 13: 161.

21. Friss, T. 1958. Thyroxine metabolism in man estimated by means of $1^{131}$-labeled L-thyroxine. Acta Endocrinol. 29: 587.

22. Brown-Grant, K., and J. R. Tata. 1961. The distribution and metabolism of thyroxine and $3: 5: 3^{\prime}$-triiodothyronine in the rabbit. J. Physiol. (London). 157: 157.

23. Gross, J., and C. P. Leblond. 1949. Distribution of microgram amounts of labeled thyroxine in the rat. Federation Proc. 8: 62. (Abstr.)

24. Appleton, W. G., and J. T. Dowling. 1965. Dynamics of hepatic thyroxine metabolism in man. Physiologist. 8: 102. (Abstr.)

25. Sterling, K., and M. A. Brenner. 1966. Free thyroxine in human serum: Simplified measurement with the aid of magnesium precipitation. J. Clin. Invest. 45: 153.

26. Beeken, W. L., W. Volwiler, P. D. Goldsworthy, L. E. Garby, W. E. Reynolds, R. Stogsdill, and R. S. Stem!er. 1962. Studies of $\mathrm{I}^{131}$-albumin catabolism and distribution in normal young male adults. J. Clin. Invest. $41: 1312$.

27. Seal, U. S., and R. P. Doe. 1964. Purification, some properties and composition of the corticosteroid- and thyroxine-binding globulins from human serum. In Proceedings of the 2nd International Congress of Endocrinology, London. Excerpta Medica Foundation, New York. Part I : 325.

28. Oppenheimer, J. H., G. Bernstein, and J. Hasen. 1967. Estimation of rapidly exchangeable cellular thyroxine from the plasma disappearance curves of simultaneously administered thyroxine- ${ }^{181} \mathrm{I}$ and albumin- ${ }^{-205} \mathrm{I}$. J. Clin. Inz'cst. 46: 762. 